\title{
EL DELITO DE DETENCIÓN ILEGAL SIN DAR RAZÓN DEL PARADERO DE LA VÍCTIMA: DIFICULTADES INTERPRETATIVAS DE LA REGULACIÓN ESPAÑOLA
}

Ramón Ragués i Vallès*

I. Introducción; II. ¿Es la desaparición de una persona un becho imputable?; III. La lesividad propia de la detención ilegal sin dar razón del paradero de la víctima; IV. Algunas repercusiones prácticas; $V$. Conclusiones.

\section{Introducción}

Cuando a principios de la década de 1990 un servidor estudiaba la Parte Especial del Derecho Penal español con el Manual de Juan Bustos -por aquel entonces catedrático en la Universitat Autònoma de Barcelona- una de las cuestiones que más le llamó la atención fue que el delito de detención ilegal sin dar razón del paradero de la víctima (actual art. $166 \mathrm{CPE}$, antiguo art. $483 \mathrm{CPE} 73$ ) se encuadrase en el capítulo dedicado a los "Delitos contra la Humanidad". Según Bustos, "estos delitos tienen elementos en común: atacan al ser humano global e internacionalmente (...) se ataca al sujeto en cuanto persona y generalmente en cualquiera (o en todas las dimensiones) consideradas hasta ahora".

Dicha ubicación resultaba sorprendente por dos grandes razones: en primer lugar, porque la categoría de los delitos de lesa humanidad no existía como tal en el entonces vigente Código Penal español, que encuadraba la citada modalidad de detención ilegal entre los delitos contra la libertad y seguridad; de hecho, la categoría de los delitos contra la humanidad no se introduciría en el Derecho penal español hasta 2003 (actual art. 607 bis $^{2}$ ). En segundo término, el emplazamiento escogido por Juan Bustos y su justificación llamaban la atención

\footnotetext{
* Profesor Titular de Derecho Penal, Universitat Pompeu Fabra, Barcelona.

${ }^{1}$ Bustos Ramírez, Manual de Derecho Penal. Parte Especial, 2. " ed., Barcelona, 1991, p. 156.

${ }^{2}$ En este precepto se incluye ahora un castigo específico "con la pena de prisión de 12 a 15 años" para quienes "detuvieran a alguna persona y se negaran a reconocer dicha privación de libertad o a dar razón de la suerte o paradero de la persona detenida". Sin embargo, este hecho sólo se castiga como delito de lesa humanidad si forma parte "de un ataque generalizado o sistemático contra la población civil o contra una parte de ella", añadiendo que "en todo caso, se considerará delito de lesa humanidad la comisión de tales hechos: (1) Por razón de la pertenencia de la víctima a un grupo o colectivo perseguido por motivos políticos, raciales, nacionales, étnicos, culturales, religiosos o de género u otros motivos universalmente reconocidos como inaceptables con arreglo al derecho internacional. (2) En el contexto de un régimen institucionalizado de opresión y dominación sistemáticas de un grupo racial sobre uno o más grupos raciales y con la intención de mantener ese régimen".
} 
Ragués - El delito de detención ilegal...

porque en aquel momento la constitucionalidad de dicho delito era puesta en tela de juicio por buena parte de la doctrina española, que entendía que la grave pena prevista de reclusión mayor (veinte años y un día a treinta años de privación de libertad) sólo podía justificarse por una sospecha de asesinato de la persona detenida que resultaba totalmente incompatible con el derecho constitucional a la presunción de inocencia y con el principio de culpabilidad ${ }^{3}$.

La redacción entonces vigente parecía justificar estas críticas al disponer, literalmente, que "el reo de detención ilegal que no diere razón del paradero de la persona detenida, o no acreditare haberla dejado en libertad, será castigado con la pena de reclusión mayor" (art. $483 \mathrm{CPE73})^{4}$. Actualmente el texto se ha modificado, estableciendo el vigente art. $166 \mathrm{CPE}$ que "el reo de detención ilegal o secuestro que no dé razón del paradero de la persona detenida será castigado, según los casos, con las penas superiores en grado a las señaladas en los artículos anteriores de este capítulo, salvo que la haya dejado en libertad" ${ }^{5}$. La diferencia básica radica en que en la versión ya derogada el Código parecía dar a entender que era el acusado quien debía probar en su descargo la puesta en libertad de la víctima ${ }^{6}$. En el Código vigente la pena es inferior a la del asesinato, pues se parte de un mínimo de diez años y un día (art. 164 en relación con el 166 CPE) hasta un máximo de veintidós años y seis meses (cuando concurren, además de la desaparición, la figura del secuestro y una privación de libertad de más de quince días: cfr. art. $164 \mathrm{CPE})^{7}$.

\footnotetext{
3 En relación con la regulación del art. 483 CPE73 QuERALT JimÉNEZ, Derecho penal español. Parte

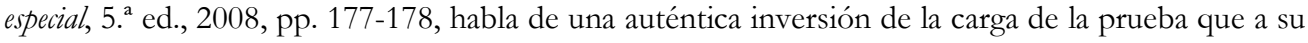
juicio sigue en cierta medida vigente en la actual regulación. También muy críticos con el antiguo art. 483 CPE73 BAjO FERnÁNDEZ, Manual de Derecho Penal (Parte Especial). Delitos contra la libertady seguridad, honestidad, honor y estado civil, Madrid, 1989, pp. 34-35; y LANDROVE DÍAZ, Detenciones ilegales y secuestros, Valencia, 1999, p. 169. Para más referencias de autores contrarios a la constitucionalidad del precepto cfr. DíEz Ripollés, en ID./Gracia Martín (coords.), Comentarios al Código Penal. Parte especial, vol. I, Valencia, 1997, pp. 755-758 (nota 232), quien también manifiesta sus dudas sobra la legitimidad constitucional del precepto vigente; y GARCÍA PÉREZ, "Delitos de sospecha: principio de culpabilidad y derecho a la presunción de inocencia: los artículos 483 y 485 CP”, Anuario de Derecho Penaly Ciencias Penales, 1993, p. 652 ss.

${ }^{4}$ Se hace eco de estas críticas la Sentencia de la Audiencia Provincial de Madrid de 15 de junio de 1999 (Sección 17. a , ponente Fernández Entralgo), en la que se afirma, haciendo también referencia al delito de sustracción de menores, que "muchos penalistas criticaron ambas modalidades delictivas como tipos de sospecha, escasamente compatibles con las exigencias de la presunción (impropia, en realidad, afirmación normativa interina) de inocencia, consagrada por el inciso final del apartado segundo del artículo 24 de la vigente Constitución Española”.

${ }^{5}$ Una perspectiva histórica de la regulación española sobre la materia en MUÑAGORRI LAGUÍA, "La 'construcción' del delito de detención ilegal con desaparición forzada. La jurisprudencia constitucional y el artículo 483 del Código Penal”, Poder Judicial, 27 (1992), pp. 109-148.

${ }^{6}$ Con todo, la doctrina posterior sigue expresando sus reservas sobre la compatibilidad del precepto con la presunción de inocencia: en tal sentido, cfr. DíAZ-MAROTO Y VILLAREjo, en BAjO FERnÁndeZ (dir.), Compendio de Derecho Penal (Parte Especial), vol. II, Madrid, 1998, p. 51. También se manifiestan ciertas dudas por parte de REBOLLO VARGAS, en CÓRDOBA RODA / GARCía ARÁN (dirs.), Comentarios al Código Penal. Parte especial, tomo I, Madrid-Barcelona, 2004, p. 191.

${ }^{7} \mathrm{La}$ pena del asesinato oscila entre los quince y los veinticinco años (arts. 139 y $140 \mathrm{CPE}$ ).
} 
Discrepando radicalmente de buena parte de sus colegas españoles, Juan Bustos afirmaba en su Manual "que lo básico es justamente el hecho de la desaparición forzada (...) y es ese hecho lo que afecta al bien jurídico (...). No estamos ante un delito de sospecha contra la vida, sino ante un delito de lesión contra la identidad como persona del sujeto pasivo y en el hecho de que la desaparición forzada que lo constituye es sin lugar a dudas susceptible de ser probado" ". Sostenía Bustos:

"En la actualidad, la difusión en muchos países de la práctica de este delito, obliga a considerar estos hechos desde una nueva perspectiva (...) ya que se está violando además de la libertad, el reconocimiento de bienes de carácter internacional del sujeto, así el art. 6 de la Carta Internacional de Derechos Humanos y el art. 16 del Pacto Internacional de Derechos Civiles y Políticos señalan: 'Todo ser humano tiene derecho en todas partes al reconocimiento de su personalidad jurídica'. Y ello se expresa en su posibilidad de una multiplicidad de actos en la vida jurídicosocial, que aparecen negados con el desaparecimiento, desde los más simples y personales, hasta el de ser reconocida su muerte; en definitiva el derecho reconocido a mantener su identidad de persona humana tanto en la vida como en la muerte, cuestión fundamental en la historia del hombre y de la humanidad y que es lo que ha determinado su acervo y evolución histórica, cultural y ética. Es eso lo que hace aumentar enormemente el 'daño' de este hecho, constituyendo un ataque más profundo que el simple homicidio, pues no afecta sólo a la vida, sino al hombre en todas sus dimensiones"'.

La particular posición de Bustos se explicaba, sin duda, por los gravísimos crímenes acontecidos tanto en su país natal como en otros de Latinoamérica durante las décadas anteriores, lo que muy probablemente le había permitido adquirir una perspectiva acerca de la lesividad de estos hechos que no tenían sus colegas en España, donde la aplicación de este delito era entonces muy poco

\footnotetext{
${ }^{8}$ De acuerdo con el homenajeado, Muñoz CONDE, Derecho Penal. Parte especial, 7. ${ }^{a}$ ed., Valencia, 1988, p. 144, afirmaba que "no le falta, por tanto, razón a Bustos, cuando considera que estamos aquí ante un caso de 'desaparición forzada de personas' que constituye incluso un ataque más profundo que el simple homicidio”. También se situaba en posiciones próximas GIMBERNAT ORDEIG, "El delito de detención ilegal con desaparición forzada", en AAVV, Estudios Penales en memoria del Profesor Agustín Fernández-Albor, Santiago de Compostela, 1989, pp. 361-363; y MARTíN PALLín, "Desaparición forzada de personas: de la sospecha al reproche penal", Actualidad Penal, 1989-1, pp. 1005-1009.

9 Bustos Ramírez, Parte Especial, pp. 158-159. Más recientemente retoma algunas de estas ideas HormazÁbal MALARÉE, “Torturas y desaparición forzada de personas”, Revista General de Derecho Penal, 9 (2008), aptdo. 3.
} 
Ragués - El delito de detención ilegal...

frecuente $^{10}$. Sea como fuere, en aquella misma época los Tribunales españoles le dieron en parte razón, pues la constitucionalidad del artículo sería refrendada tanto por el Tribunal Supremo como por el Tribunal Constitucional, aunque sin llegar a pronunciarse sobre la cuestión concreta de si se trataba o no de un delito contra la humanidad $^{11}$.

No ha sido hasta más recientemente cuando el Derecho penal internacional -y más concretamente el Estatuto de Roma (1998, en vigor desde 2002)- han atribuido tal condición a la desaparición forzada de personas, aunque sólo cuando tal delito "se cometa como parte de un ataque generalizado o sistemático contra una población civil" (art. 7.1.i ECPI). En tal sentido, la perspectiva del homenajeado de que la desaparición de una única persona ilegalmente detenida supone un delito contra la humanidad, en cualquier circunstancia y con independencia de quien sea su autor, no ha prosperado por el momento en el proceso de creación normativa internacional.

Precisamente a estas cuestiones quieren dedicarse las siguientes páginas. En ellas se analizará, en primer lugar, qué significa la desaparición de una persona y en qué términos puede ser imputada a alguien (II), para seguidamente estudiar cuál es la lesividad propia del delito de detención ilegal sin dar razón del paradero de la víctima y si dicha lesividad justifica el vigente tratamiento punitivo de tales comportamientos (III). Por último, se expondrán algunas otras repercusiones prácticas derivadas de dicho concepto (IV). Aunque el punto de partida de este trabajo, al igual que de las anteriores consideraciones de Juan Bustos, es el Derecho

\footnotetext{
${ }^{10}$ Una perspectiva más reciente sobre estos crímenes y su tratamiento por la Corte Interamericana de Derechos Humanos en CiTRONI, "Desaparición forzada de personas': desarrollo del fenómeno y respuestas de la Corte Interamericana de Derechos Humanos", Anuario de Derecho Internacional, 19 (2003), pp. 373-407.

${ }^{11}$ En su Sentencia de 25 de junio de 1990 (ponente Ruiz Vadillo) sobre el denominado caso de "El Nani" (apodo de un delincuente común que fue detenido por agentes de la Policía Nacional sin que haya vuelto a conocerse su paradero) el Tribunal Supremo español justificó la gravedad de las sanciones previstas para este delito con las siguientes palabras: "la Ley Penal establece una pena progresiva más alta en función del tiempo que dura la detención ilegal y nadie discute la legitimidad de tal agravación y fija, por último, una pena superior cuando ni siquiera se conoce cuánto va a durar la privación puesto que el hecho probado afirma que no se conoce el paradero del detenido. No hay en el precepto sospechas de muerte ni siquiera de atentado a la integridad, sino constatación de un hecho indiscutible: que al detenido no se le puso en libertad". La legitimidad de estos razonamientos fue confirmada por el Tribunal Constitucional en su Auto 421/1990, de 28 de noviembre, en el que inadmitió el recurso de amparo interpuesto por los agentes condenados. Según refiere García PÉREZ, Anuario de Derecho Penal y Ciencias Penales, 1993, p. 629, a raíz del caso de "El Nani" una parte significativa de la doctrina española pasó a declarase partidaria de la constitucionalidad del precepto. Un detenido análisis de esta resolución en LANDROVE DíAZ, Detenciones ilegales, pp. 177-183; y MARTín PALLín, Actualidad Penal, 1989-1, pp. 1005-1009.
} 
español, los argumentos que se expondrán a continuación pretenden ser aprovechables mutatis mutandi para cualquier regulación similar.

\section{II. ¿Es la desaparición de una persona un hecho imputable?}

Un primer dilema al que conviene enfrentarse de manera ineludible antes de analizar la lesividad propia de este delito es la posibilidad de considerar la desaparición de una persona como un hecho o como un resultado imputable a un determinado individuo. Ciertamente a semejante cuestión puede responderse en un sentido negativo, entendiendo que la situación de desaparición no es en realidad un hecho, sino la simple constatación de la incapacidad del sistema judicial para reconstruir qué ha sucedido realmente con la víctima inicialmente privada de libertad $^{12}$ : resulta obvio que las personas - $\mathrm{O}$ sus cuerpos- no desaparecen sin más de la faz de la tierra.

A ello cabe replicar, no obstante, que la desaparición en sí misma, aun ignorándose el desenlace, no deja de ser un determinado estado de cosas o una modificación de la realidad en un determinado sentido que, con independencia de su carácter más o menos tangible, puede bastar para configurar un resultado típico consistente en la ausencia de una concreta persona en un concreto entorno que se ve dañado por dicha ausencia ${ }^{13}$. No mucho más tangibles son otros resultados a los que a menudo se atribuye la condición de tales, como por ejemplo la puesta en peligro concreta en aquellos delitos que la exigen o la lesión de los bienes jurídicos supraindividuales.

\footnotetext{
12 DíEZ Ripollés, en Comentarios, p. 757, manifiesta que la desaparición "simplemente significa el desconocimiento del lugar donde se encuentra algo o alguien al no hallarse en su espacio habitual o previsto; en este caso no es más que la ignorancia sobre lo que ha sucedido con el objeto material del delito, con la persona detenida. Pero tal ignorancia lo único que refleja es las limitaciones de la Administración de justicia en el esclarecimiento de los delitos". En el mismo sentido GARCía PÉreZ, Anuario de Derecho Penaly Ciencias Penales, 1993, p. 660: “en mi opinión el Derecho penal no puede utilizar esta situación, que a lo sumo se puede calificar de verdad formal pero no material, para justificar intervenciones penales que, como en el caso del art. 483 CP, implican la perdida de un derecho fundamental consagrado por el art. 17.1 de la Constitución".

13 En estos términos se pronuncia Gimbernat Ordeig, en Estudios Penales, p. 363, quien viene a sostener que la desaparición es un hecho demostrable y susceptible de imputación. También así se pronuncia la ya citada supra Sentencia de la Audiencia Provincial de Madrid de 15 de junio de 1999, afirmando, en referencia a previos pronunciamientos del Tribunal Supremo que "a través de una actividad probatoria desarrollada con todas las garantías en el juicio oral se han declarado probados los datos y circunstancias que han servido de base a la condena, que una persona ha sido detenida, que su detención puede considerarse ilegal, que al detenido no se le puso en libertad y que ha desaparecido. Esos elementos fácticos no son hechos negativos, sino comprobables, y han podido ser probados por la acusación" (negrita añadida). En tal sentido se discrepa de la opinión de autores como DíEZ RipolLÉs, en Comentarios, pp. 756-757, quien entiende que la acusación sólo satisface la carga de la prueba cuando acredita el desenlace final de la inicial privación de libertad.
} 
Ragués - El delito de detención ilegal...

Con todo, aun aceptando que la desaparición pueda ser descrita como un hecho desde la perspectiva de la administración de justicia y de la propia sociedad no debe ignorarse que aquello que se caracteriza como "desaparición" no es sino un gran interrogante con diversos desenlaces posibles que, en caso de ser desvelados, podrían tener repercusiones distintas $-\mathrm{y}$ no necesariamente negativasen su valoración. Así, mientras la conducta de sustraer a una persona contra su voluntad de su entorno cotidiano y mantenerla indefinidamente privada de libertad es, desde luego, un acto que se hace acreedor de un importante reproche social, la decisión espontánea del mismo sujeto de iniciar una nueva vida en otro lugar del planeta sin comunicárselo a nadie no es sino un acto de ejercicio de la libertad que debe ser respetado, por más que pueda disgustar a las personas próximas. En definitiva: pueden existir desapariciones queridas y no queridas por la víctima $\mathrm{y}$, por tanto, irrelevantes o relevantes desde el punto de vista del Derecho penal.

En consecuencia, el estado de cosas al que se alude con el término "desaparición" se presta a un juicio ambivalente cuya resolución definitiva permanece en suspenso hasta que se conozca el desenlace final, si es que llega tal día. Este desenlace repercute asimismo en las posibilidades de imputación de la desaparición al responsable de la privación de libertad previa a dicha desaparición. Así, de manera evidente las desapariciones buscadas por la víctima una vez recuperada la libertad no son imputables a quien inicialmente la detuvo o encerró y entre las desapariciones no queridas no todas son imputables al responsable de la inicial privación de libertad, no procediendo tal imputación cuando, por ejemplo, durante la fase inicial se haya perdido absolutamente el control sobre la víctima por la intervención de un tercero: en el caso, por ejemplo, en que una segunda banda de secuestradores se apodera de la persona detenida sustrayéndola de la organización que inicialmente la privó de su libertad.

Algunos autores apuntan a que en estos casos concurre la estructura propia de la injerencia. Así, la privación inicial de libertad supondría la creación de una situación de riesgo de desaparición para el sujeto pasivo que permitiría con los criterios de imputación propios de la comisión por omisión atribuir al sujeto activo de la detención el posterior estado de ignorancia del paradero de la víctima ${ }^{14}$. Con todo, el hecho de que puedan existir -por lo menos teóricamente- desapariciones imputables a la víctima o a terceros impiden afirmar de manera automática que el responsable de la privación inicial siempre que lo haya de ser de la posterior desaparición.

Partiendo de estas premisas, procede reconstruir, desde la perspectiva de un espectador omnisciente, es decir, libre de las limitaciones de conocimiento de las autoridades policiales y judiciales, cuáles son los posibles desenlaces

\footnotetext{
${ }^{14}$ Entre éstos cabe citar al propio Bustos RamíReZ, Parte especial, p. 159, quien afirma en referencia al art. 483 CPE73 que "se trata pues de un comportamiento omisivo, cuyo fundamento estaría en la injerencia de un sujeto en el desarrollo del otro, que lo convierte en garante respecto de su persona”.
} 
imaginables cuando una persona ha sido privada de su libertad y, una vez descubierto, el responsable de tal privación no justifica su paradero:

1. ${ }^{\circ}$ En primer lugar cabe imaginar que la privación de libertad -en paradero desconocido para las autoridades- se mantenga todavía en el momento en el que el caso llega a conocimiento de la justicia. Esta situación puede concurrir en dos posibles escenarios $^{15}$ :

a) Que el mantenimiento de la privación de libertad sea imputable al sujeto que se niega a revelar el paradero de la víctima en el procedimiento penal. Por ejemplo, en el caso en que se lleve a juicio al jefe de una organización criminal responsable del secuestro de un político y éste se niegue a explicar en qué lugar sus subordinados mantienen encerrada a la víctima.

b) Que el mantenimiento de dicha situación no sea ya imputable al acusado, por ejemplo, si éste intervino en la ejecución inicial de la detención y efectuó labores de vigilancia pero con posterioridad el rehén fue capturado por otra banda criminal.

2. ${ }^{\circ}$ Que la privación de libertad haya finalizado al llegar el día del juicio ${ }^{16}$. Esta hipótesis puede presentarse en los siguientes escenarios:

a) Que la víctima haya muerto durante la privación de libertad y su cadáver no haya podido ser hallado, negándose el acusado a revelar tal circunstancia en el juicio.

b) Que la víctima haya recuperado la libertad, ya sea por sus propios medios, por iniciativa de terceros o por iniciativa del acusado, pero haya decidido libremente no regresar a su entorno originario ni comunicar tal decisión a sus allegados.

Consecuentemente el estado de cosas denominado "desaparición" se caracteriza, en primer lugar, por la ausencia de una persona de su entorno cotidiano y, en segundo término, por un gran interrogante sobre cuál de los anteriores desenlaces se ha producido. De estos posibles desenlaces algunos supondrían, en caso de llegar a conocerse, una mayor responsabilidad para el acusado (por ejemplo, cuando se le pudiera atribuir la muerte de la víctima o el mantenimiento de su privación de libertad), mientras que otros limitarían dicha responsabilidad a la privación de libertad inicial (huida de la víctima o pérdida de

\footnotetext{
15 Otra reconstrucción de posibles desenlaces de la desaparición en DíEZ RIPOLLÉS, en Comentarios, pp. 756-757.

${ }^{16}$ Queralt JimÉNEZ, Parte especial, p. 177, interpreta que la desaparición supone una prolongación indefinida de la libertad de la víctima y que ésta es la razón del incremento punitivo al acentuarse la antijuricidad de la acción inicial. También en este sentido se pronuncian CARBONELL Mateu/GonzÁlez Cussac, en Vives Antón et al., Derecho penal. Parte especial, 2.a ed., Valencia, 1990, p. 168. Sin embargo, los argumentos expuestos supra acreditan que en el plano teórico son imaginables perfectamente otros desenlaces.
} 
Ragués - El delito de detención ilegal...

control sobre ella) y algunos incluso podrían suponer una atenuación de la responsabilidad del sujeto en caso de considerarse probados (puesta en libertad espontánea de la víctima).

Con todo, a la vista del haz de desenlaces posibles no puede pasarse por alto que aquellos casos en los que la desaparición es imputable al propio sujeto privado de libertad o a terceros son altamente improbables, pues de acuerdo con la experiencia es algo ciertamente muy poco habitual que una persona secuestrada recupere la libertad y decida no comunicarlo a sus allegados manteniéndoles intencionadamente en una dolorosa incertidumbre; y también es altamente improbable que alguien sea secuestrado por terceros cuando previamente se hallaba ya privado de su libertad por otras personas. Así, cabe matizar que, si bien el estado llamado "desaparición" no es otra cosa que un gran interrogante con varias respuestas posibles de distinto signo que impiden una valoración automáticamente negativa y su imputación al sujeto responsable de la inicial privación de libertad, en la práctica la probabilidad de que el desenlace sea desfavorable para los intereses de la persona privada de libertad e imputable al responsable de la detención resulta muchísimo más elevada.

A diferencia de la panorámica de la que disfruta el espectador omnisciente, cuando en la práctica los casos de desaparición forzada llegan a juicio resulta imposible reconstruir con exactitud cuál ha sido el verdadero desenlace y simplemente existe constancia de que un determinado acusado ha intervenido responsablemente en la privación de libertad de otro individuo cuyo paradero actual se desconoce. En dicho contexto cabe imaginar varias reacciones posibles por parte del sujeto activo que, aun produciéndose en el momento del enjuiciamiento, no dejan de tener relevancia típica por cuanto una peculiaridad del art. $166 \mathrm{CP}$ es que el resultado de desaparición continúa en el tiempo y perdura hasta el momento en el que el juez dicta sentencia, dependiendo la propia tipicidad del hecho de cuál sea la actitud del acusado durante la instrucción y el posterior juicio. Tales reacciones pueden ser las siguientes:

a) $\mathrm{El}$ acusado dice conocer dónde se encuentra la víctima pero se niega a revelarlo al tribunal. En tal caso es evidente que no puede presumirse en su contra la causación de la muerte de la persona privada de libertad, pero, en cambio, no parece existir el menor problema para afirmar que la desaparición es un estado de cosas que le resulta imputable.

b) El acusado reconoce haber ocasionado la muerte de la víctima: si esta declaración se considera verosímil podrá ser condenado por asesinato y, aún en el caso de entenderse que semejante manifestación no basta para imponer tal condena por no ser prueba suficiente, sí podrá imputársele en todo caso el hecho de la "desaparición".

c) Si el acusado se niega a declarar, ciertamente no podrá presumirse en su contra el que la víctima siga privada de libertad o haya sido asesinada, pero la presunción de inocencia en modo alguno debe impedir que se le impute un hecho acreditado, 
como es la desaparición de la persona privada de su libertad cuando ha quedado acreditada su intervención en la privación inicial.

d) El acusado manifiesta en su descargo haber puesto en libertad a la víctima o haber perdido el control sobre ella. De forma evidente ésta es la situación más complicada de resolver, pues en caso de prosperar semejantes alegaciones la desaparición no podrá imputarse al procesado. Para dar una respuesta es necesario distinguir entre dos posibles escenarios:

d) La alegación del acusado carece del más mínimo soporte indiciario, ya sea porque el juicio es el primer momento en el que la manifiesta o porque habiéndola sostenido ya en la instrucción, y habiendo sido debidamente investigada, no se ha obtenido el más mínimo elemento indiciario que la sostenga.

d") La alegación cuenta con indicios (no necesariamente pruebas) que la hacen mínimamente creíble.

Si bien en este último caso ( $d$ ”) existe una situación de duda que, aun siendo tenue, el juez o tribunal deben resolver a favor del acusado, en los anteriores supuestos, por el contrario, no debe existir problema alguno para considerar al acusado responsable de una desaparición no deseada por la víctima. Ello se explica porque de acuerdo con los criterios más extendidos en materia probatoria, cuando existe prueba inicial de cargo de un determinado hecho inculpatorio compete al acusado la aportación de aquellos posibles contraindicios que desvirtúen dicha prueba y puedan hacer dudar al juez, sobre todo cuando los desenlaces alternativos resultan tan altísimamente improbables como para convertir cualquier duda en poco razonable. Así, el becho de que se demuestre que una persona ha intervenido en la privación de libertad de otra y que esta última ha desaparecido resulta ser prueba de cargo suficiente, de acuerdo con la experiencia, para imputar al acusado el estado de cosas denominado "desaparición no querida de la víctima" y sólo en el caso de que el acusado alegue la concurrencia de un desenlace que le exonere y sea capaz de aportar algún contraindicio que haga razonable tal alegación se deberá renunciar a imputar la desaparición.

En tal sentido cabe destacar la fundamentación jurídica de la Sentencia de la Audiencia Provincial de Madrid de 15 de junio de 1999 en la que se afirma que:

$[\mathrm{U}$ na cosa es que no se imponga al acusado realizar prueba alguna del destino del desaparecido y otra, bien distinta, es que, constatada la desaparición, haya de aceptarse la verosimilitud de su alegación sobre la presunta huida del detenido, pues la presunción de inocencia no alcanza a la de veracidad de esas explicaciones, como parece pretender el recurrente.

Tal conclusión -debe insistirse- en modo alguno se opone al derecho fundamental a la presunción de inocencia, pues evidentemente este derecho no garantiza a los acusados el que cualquier alegación en su descargo haya de ser acogida como duda 
Ragués - El delito de detención ilegal...

razonable si no concurre el más mínimo indicio que la soporte cuando, por el contrario, existe prueba de signo incriminatorio que apunta a la culpabilidad. Como afirma el Tribunal Supremo español en su Sentencia de 7 de diciembre de 2005 (ponente Colmenero Menéndez de Luarca), "cuando exista una prueba de cargo que pueda considerarse consistente, no puede aceptarse como suficiente la expresión desnuda y simple de la duda, sino que será precisa la existencia de algún dato o elemento, explícito o implícito pero siempre accesible, que permita una explicación comprensible de la desestimación de las pruebas de la acusación. Así podrá comprobarse la racionalidad de la duda y la ausencia de arbitrariedad".

\section{La lesividad propia de la detención ilegal sin dar razón del paradero de la víctima}

Una vez sentada la premisa de que la desaparición no querida de una persona es un estado de cosas imputable procede analizar su lesividad. Para ello conviene desprenderse de entrada de todos aquellos calificativos que a menudo se asocian a estos hechos con la voluntad de expresar su gravedad pero que resultan poco clarificadores para determinar el daño que causan. Afirmar, por ejemplo, que la desaparición forzada ataca al individuo en tanto que persona o a escala internacional no contribuye a aclarar la cuestión de cuál es la lesividad de tal estado de cosas, sino más bien a oscurecerla por cuanto tal respuesta invita a plantearse inmediatamente la ulterior pregunta sobre qué tienen estos hechos -en comparación con otros igualmente muy graves- que les confiere esta capacidad de atacar la propia esencia del individuo o adquirir esta trascendencia supranacional ${ }^{17}$. En consecuencia, conviene dejar de lado todos estos calificativos, que en el fondo tienen una naturaleza ya jurídica, para preguntar, en términos prejurídicos, cuál es el daño que en términos personales y sociales causa la desaparición forzada de un ciudadano. Ello, por cierto, sin la más mínima voluntad de restar un ápice de gravedad a tan terribles actos, sino sólo con el ánimo de dilucidar qué tienen estos hechos que, según expone el homenajeado, los hace más graves que otros actos igualmente terribles, como una violación o un asesinato.

Desde el punto de vista de la víctima la privación de libertad supone, de entrada, un ataque contra su libertad ambulatoria. Este primer aspecto explica ya por sí solo una parte sustancial del daño que causa este delito, al que se añade una importante afectación a la seguridad de la misma víctima, quien no sólo ve

\footnotetext{
${ }^{17}$ Crítico con Bustos García PÉreZ, Anuario de Derecho Penal y Ciencias Penales, 1993, p. 658, quien sostiene que la postura del homenajeado "no logra identificar un bien jurídico diferenciado que permita desterrar la sospecha de que se ha dado muerte a la víctima; tras señalar que junto a la libertad se lesiona el derecho al reconocimiento de la personalidad jurídica, al proceder a la concreción de este bien jurídico, la vida o la extinción de ésta, es decir, la muerte constituyen su contenido esencial. Con ello lo único que se hace es, o bien integrar la vida como bien jurídico en otro más amplio, o bien enmascarar simplemente el bien jurídico vida bajo otro nombre para evitar la presunción de muerte. De las afirmaciones del propio Bustos se infiere que detrás de la desaparición lo que realmente existe es un ataque a la vida".
} 
restringida su capacidad de movimientos, sino que, por lo general, se verá obligada a vivir la detención en una situación de grave incertidumbre sobre cuál será su destino final ${ }^{18}$. A ello se suma el daño que con la misma privación y la posterior desaparición se causa a las personas del entorno del sujeto pasivo, que se ven obligadas a vivir inicialmente en la incertidumbre sobre el bienestar de su ser querido y, a medida que van transcurriendo los años, a tener que soportar un estado de resignada duda sobre lo que pueda haberle sucedido. Este último daño, desde luego, permite constatar la existencia de una lesividad superior a la que concurre en los casos "normales" de detención ilegal que nada tiene que ver con el castigo de meras sospechas y que justifica una mayor intensidad en la respuesta punitiva. Si además se impone algún tipo de condición para liberar a la víctima -como sucede con el delito de secuestro en la regulación española (art. 164 CPE)- existirá una lesión adicional de la libertad de aquellas personas a quienes se exija.

Algún autor ha apuntado a la posibilidad de que el plus de lesividad pudiera radicar en la actitud negativa del acusado a dar razón del paradero de la víctima, es decir, en una suerte de desobediencia a la administración de justicia ${ }^{19}$. Sin embargo, semejante interpretación parece difícilmente conciliable con el derecho del acusado a no declarar contra sí mismo, máxime en aquellos supuestos en los que el descubrimiento del paradero de la víctima supondría la aportación de pruebas en su propia contra.

Por el contrario resulta más dudoso que en estas situaciones pueda hablarse per se -como sostiene Juan Bustos en su Manual- de un daño añadido consistente en la negación a la víctima de su propia identidad personal. En tal sentido cabe señalar que la privación de libertad y posterior desaparición de una persona no necesariamente ha de entrañar una amenaza al reconocimiento de su identidad como ciudadano, especialmente cuando existen procedimientos judiciales para tratar de localizarla y por parte del Estado se advierte una preocupación real por esclarecer lo sucedido. Si se parte de la premisa de que es la sociedad, por medio de los poderes públicos, quien reconoce jurídicamente la identidad de sus miembros, resulta difícilmente sostenible que el autor individual de un delito pueda eliminar la identidad de otra persona cuando las autoridades la siguen reconociendo por medio de la correspondiente indagación policial y judicial.

\footnotetext{
${ }^{18}$ La idea de que con los delitos de detención ilegal y secuestros no sólo se castiga una restricción de la libertad de movimientos de la víctima, sino además la situación de incertidumbre que se crea tanto en la propia víctima como en las personas de su entorno, se desarrolla en RAGUÉS I VALLÈS, "La delimitación entre detenciones ilegales y coacciones. ¿Una tarea condenada al fracaso?", Actualidad Penal, 11 (2003), pp. 309-331.

19 BAjo FernándeZ, Parte especial, p. 34, apunta como posible explicación de la severidad de las penas a "que a la gravedad del hecho de la propia detención, el delincuente añade la dificultad, intencionadamente creada por él, de no colaborar con la Administración de Justicia". También se plantea esta posible explicación por DíAZ-MAROTO Y VILLAREjO, en Compendio, p. 51. La crítica a que esta interpretación vulnera el derecho fundamental a no declarar contra uno mismo ha sido formulada por García PÉREZ, Anuario de Derecho Penal y Ciencias Penales, 1993, p. 662.
} 
Ragués - El delito de detención ilegal...

En cambio, en aquellos casos en los que la desaparición resulta de algún modo imputable al Estado sí existe una capacidad -de la que el delincuente común carece- de atentar contra la identidad de la víctima. Sin embargo, para que tal amenaza exista además de la actuación de concretos funcionarios o agentes de la autoridad -cuya condición, de hecho, ya es un factor de agravación en el Derecho vigente (art. $167 \mathrm{CPE}$ )- será necesario que concurra también una auténtica pasividad por parte de los responsables -policiales y judiciales- del esclarecimiento de lo sucedido. En este último contexto cabrá plantearse adicionalmente la dimensión internacional del delito, al entrar en consideración una de las ideas básicas del Derecho penal internacional, como es el principio de que un delito adquiere dimensión supranacional cuando el Estado donde se ha cometido no tiene interés o no puede perseguirlo (el llamado "principio de complementariedad" reconocido en el art. 17 ECPI ${ }^{20}$.

De hecho, los principales textos internacionales limitan a estas situaciones los supuestos de "desaparición forzada de personas". Así, por ejemplo, según la (todavía no vigente ${ }^{21}$ ) Convención Internacional de Naciones Unidas para la protección de todas las personas contra las desapariciones forzadas (2006, firmada por España en 2007 aún no ratificada en 2009) tal desaparición es "el arresto, la detención, el secuestro o cualquier otra forma de privación de libertad que sean obra de agentes del Estado o por personas o grupos de personas que actúan con la autorización, el apoyo o la aquiescencia del Estado, seguida de la negativa a reconocer dicha privación de libertad o del ocultamiento de la suerte o el paradero de la persona desaparecida, sustrayéndola a la protección de la ley" (art. 2) ${ }^{22}$. Este mismo convenio establece (art. 5) que (únicamente) "la práctica generalizada o sistemática de la desaparición forzada constituye un crimen de lesa humanidad"23.

20 También Hormazábal Malarée, Revista General de Derecho Penal, 9 (2008), aptdo. 3.1, se muestra partidario de distinguir entre la desaparición forzada común -que desde su perspectiva sólo atenta contra la libertad ambulatoria- y aquélla imputable al Estado.

${ }^{21}$ En mayo de 2009 aún no la han ratificado los veinte estados necesarios para su entrada en vigor, aunque la han firmado ya ochenta y un países.

${ }^{22}$ En términos similares el art. 2 de la Convención Interamericana sobre Desaparición Forzada de Personas (1994) establece que "se considera desaparición forzada la privación de la libertad a una o más personas, cualquiera que fuere su forma, cometida por agentes del Estado o por personas o grupos de personas que actúen con la autorización, el apoyo o la aquiescencia del Estado, seguida de la falta de información o de la negativa a reconocer dicha privación de libertad o de informar sobre el paradero de la persona, con lo cual se impide el ejercicio de los recursos legales y de las garantías procesales pertinentes". Sobre el proceso de regulación internacional de este delito cfr. AGUILAR CAVALlo, "El reconocimiento jurisprudencial de la tortura y de la desaparición forzada de personas como normas imperativas de derecho internacional público", Revista Iuris et Praxis, 12 (2006), pp. 117-154.

23 Con todo no puede ignorarse que la misma Convención establece una cláusula de jurisdicción universal para estos delitos aun cuando no merezcan la consideración de crimen de lesa humanidad. Así, el art. 9.2 dispone que "cada Estado Parte tomará asimismo las medidas necesarias para establecer su jurisdicción sobre los delitos de desaparición forzada en los casos en que el presunto autor se halle en cualquier territorio bajo su jurisdicción, salvo que dicho Estado lo extradite o lo 
En consecuencia, sólo en aquellos casos en los que se constate la intervención -activa u omisiva- del Estado en la privación de libertad y posterior desaparición del sujeto cabrá apreciar aquella lesividad que en su momento llevó a Juan Bustos a sostener que el delito de detención ilegal sin dar razón del paradero de la víctima era una infracción penal cuya dañosidad iba más allá de la simple privación de libertad y atacaba la propia personalidad jurídica de la víctima. Ello significa que cuando no exista intervención de los agentes del Estado en la comisión de tal delito y cuando las autoridades cumplan con su deber de tratar de localizar a las personas desaparecidas, dentro de su gravedad esta clase de detención ilegal será un delito común que como tal deberá ser sancionado.

La conclusión a los anteriores razonamientos es que, ciertamente, cabe defender una interpretación del delito de desaparición forzada de personas que castigue al sujeto por un estado de cosas que es en sí mismo lesivo y del que dicho sujeto es responsable y no por la sospecha de haber ocasionado resultados más graves con posterioridad a la privación inicial de libertad de la víctima. De este modo se logra justificar la existencia de tal delito y su compatibilidad con la presunción de inocencia. Sin embargo, esta perspectiva no se corresponde plenamente con la del homenajeado en su Manual, ni tampoco con la idea de que lo que se vulnera con estos delitos es el derecho de la víctima "a mantener su identidad de persona humana tanto en la vida como en la muerte". Precisamente porque en los casos "normales" de desaparición la identidad del sujeto sigue siendo reconocida por el Estado y en todo caso el daño que se ocasiona surge de la imposibilidad de conocer su paradero. Sólo en aquellos supuestos en los que el propio Estado intervenga en la desaparición de la persona colaborando en la eliminación de todos aquellos elementos acreditativos de su existencia e identidad concurrirá el daño adicional al que aludía Juan Bustos ${ }^{24}$.

Es posible que la honda impresión que los graves crímenes cometidos unos años antes en su propio país y en otros cercanos llevara al homenajeado a considerar en su Manual que cualquier delito de detención ilegal sin dar razón del paradero de la víctima había de ser considerado un delito contra la identidad del sujeto pasivo y un crimen contra la humanidad. Sin embargo, aun tratándose de

entregue a otro Estado conforme a sus obligaciones internacionales, o lo transfiera a una jurisdicción penal internacional cuya competencia haya reconocido". Por su parte, el art. 11.1 añade que "el Estado Parte en el territorio de cuya jurisdicción sea hallada la persona de la cual se supone que ha cometido un delito de desaparición forzada, si no procede a su extradición, o a su entrega a otro Estado conforme a sus obligaciones internacionales, o a su transferencia a una instancia penal internacional cuya jurisdicción haya reconocido, someterá el caso a sus autoridades competentes para el ejercicio de la acción penal".

${ }^{24}$ En tal sentido, textos como la Convención Interamericana sobre Desaparición Forzada de Personas (aprobada en 1994, en vigor desde 1996) consideran la desaparición forzada de personas como un delito especial que sólo pueden cometer "agentes del Estado" o personas que actúen con "la autorización, el apoyo o la aquiescencia del Estado". 
Ragués - El delito de detención ilegal...

hechos que siempre revisten una notable gravedad, ello no debe impedir efectuar distinciones entre los diversos supuestos imaginables y graduar el tratamiento punitivo de acuerdo con los matices expuestos. En tal sentido, estas páginas quieren situarse en un punto intermedio entre la posición de Bustos y la de sus colegas españoles que niegan la constitucionalidad de esta figura: la detención ilegal sin dar razón del paradero de la víctima es un delito cuya previsión es perfectamente respetuosa con los derechos constitucionales, pero ello no la convierte sin más, siempre y en cualquier caso, en un delito contra la humanidad con dimensión internacional.

\section{Algunas repercusiones prácticas}

De las anteriores conclusiones, fundamentalmente de las relativas a la dañosidad propia de esta figura delictiva, se extraen algunas repercusiones importantes para su aplicación práctica, que tienen que ver con el momento de su consumación y con el inicio del plazo de prescripción.

En relación con la consumación del delito existe la duda sobre el momento a partir del cual cabe hablar de que una persona privada de libertad "ha desaparecido", es decir, el instante en que ya concurre ese ulterior estado de cosas que, de acuerdo con lo expuesto, entraña una lesividad superior a la privación de libertad. Un punto a partir del cual puede constatarse tal desaparición de manera difícilmente cuestionable es aquél en que, pese a estar a disposición de la justicia, los responsables de la inicial privación de libertad no explican qué ha sucedido con la persona detenida. De hecho, el art. $166 \mathrm{CP}$ exige, como elemento del tipo objetivo del delito, que el reo "no dé razón" del paradero de la víctima, lo que presupone que existe un sujeto identificado del que se espera que revele el lugar donde se halla la persona privada de libertad.

En consecuencia, el delito de desaparición forzada de personas se consuma en el momento en que se constata que existe una desaparición que no resulta explicada por parte de quienes han participado en la privación de libertad previa.

Este estado de consumación permanece durante todo el tiempo en que la desaparición no es aclarada, lo que puede suponer que el delito no prescriba mientras sus responsables se nieguen a aportar una explicación -mínimamente verosímil- sobre el destino final de la víctima, lo que de facto puede implicar en muchos casos que el delito no prescriba mientras vivan sus responsables ${ }^{25}$.

\footnotetext{
${ }^{25}$ En tal sentido el art. 8 de la Convención Internacional de Naciones Unidas para la protección de todas las personas contra las desapariciones forzadas establece que "cada Estado Parte que aplique un régimen de prescripción a la desaparición forzada tomará las medidas necesarias para que el plazo de prescripción de la acción penal: a) Sea prolongado y proporcionado a la extrema gravedad de este delito; b) Se cuente a partir del momento en que cesa la desaparición forzada, habida cuenta del carácter continuo de este delito". Por su parte, el art. 3 de la Convención Interamericana establece en relación con el presente delito que "será considerado como continuado o permanente mientras no
} 
Finalmente cabe preguntar: ¿qué sucede cuando, pasados unos años, logra desvelarse lo sucedido y se descubre el asesinato de la persona detenida? En tal caso, partiendo de que los partícipes en la detención pueden haber sido ya castigados por el art. $166 \mathrm{CPE}$, cabe plantearse la necesidad de descontar de la pena del asesinato la previamente impuesta $-\mathrm{y}$ parcial o totalmente cumplida- por la detención ilegal. A favor de ello cabe invocar la idea de que cuando se causa la muerte de otra persona existe frecuentemente un período de incertidumbre en su entorno más o menos cercano sobre su paradero que no justifica en modo alguno la imposición de un castigo distinto del previsto para el asesinato, pues la grave pena de este delito tiene ya en cuenta las horas o días de angustia sufridos por las personas cercanas a la víctima hasta la aparición de su cadáver.

Sin embargo, discrepando de la anterior respuesta, cuando la situación de incertidumbre se haya prolongado notablemente hasta desvelarse que la víctima efectivamente ha muerto, el castigo del asesinato no deberá atemperarse tomando en cuenta la pena previamente impuesta a la detención sin dar razón del paradero de la víctima, pues con el primer delito se castiga el atentado contra la vida y con el segundo la prolongada situación de incertidumbre en la que se ha obligado a vivir a las personas allegadas y a la sociedad ${ }^{26}$. Dado que esta última supone un daño adicional y distinto del primero nada se opone al castigo de ambos delitos.

\section{Conclusiones}

1. El delito de detención ilegal sin dar razón de paradero de la víctima respeta el derecho fundamental a la presunción de inocencia siempre y cuando esté acreditado que el acusado intervino en la inicial privación de libertad y no haya sido capaz de aportar en su descargo indicios mínimamente verosímiles para hacer dudar al juez de manera razonable acerca de la posibilidad de que la víctima desaparecida haya recuperado su libertad o continue privada de ella por terceros no relacionados con dicho acusado.

2. La lesividad de la desaparición, añadida a la de la privación de libertad previa, justifica que esta modalidad de detención ilegal o secuestro reciba un tratamiento especialmente severo. Sin embargo, cuando agentes del Estado no hayan tenido intervención alguna en la comisión del delito y exista por parte de las autoridades

se establezca el destino o paradero de la víctima" y el art. 7 establece la imprescriptibilidad del delito. Sobre la jurisprudencia de la Corte Interamericana al respecto cfr. CITRONI, Anuario de Derecho Internacional, p. 389 ss.

${ }^{26}$ En tal sentido LANDrove DíAz, Detenciones ilegales, p. 186, sostiene que en el caso de aparecer finalmente viva la persona desaparecida no procedería en modo alguno autorizar el recurso de revisión de la condena. A esta opinión cabría matizar, en todo caso, que la revisión sí debería proceder en el poco probable caso en que se descubriera ex post que la desaparición era imputable al propio sujeto pasivo o a terceros. 
Ragués - El delito de detención ilegal...

un interés auténtico en localizar a la víctima no cabe entender que el delito en cuestión atenta per se contra la identidad del sujeto pasivo y no cabe sostener tampoco que se trate de un delito contra la humanidad.

3. Así las cosas, una clasificación en tres niveles de estos hechos parece ser la estructura más adecuada para su regulación: 1) Un primer tipo que contemple la modalidad común de detención ilegal sin dar razón del paradero de la víctima; 2) Un segundo tipo aplicable en el caso en que el delito haya sido cometido por funcionarios, autoridades o agentes prevaliéndose de su condición de tales pero existiendo un verdadero interés estatal por perseguir los hechos y sancionar a los responsables; 3) Finalmente, cuando se constate la colaboración estatal -activa u omisiva en la desaparición- concurrirá la modalidad más grave de delito y aquella que realmente dota a estos hechos de una dimensión auténticamente internacional. 
REJ - Revista de Estudios de la Justicia - No 12 - Año 2010

\section{BIBLIOGRAFÍA}

* Aguilar Cavallo, Gonzalo "El reconocimiento jurisprudencial de la tortura y de la desaparición forzada de personas como normas imperativas de derecho internacional público", Revista Iuris et Praxis, 12 (2006)

* Bajo Fernández, Miguel, Manual de Derecho Penal (Parte Especial). Delitos contra la libertady seguridad, honestidad, honor y estado civil, Madrid, 1989.

Compendio de Derecho Penal (Parte Especial) (dir), vol. II, Madrid, 1998.

* Bustos Ramírez, Juan, Manual de Derecho Penal. Parte Especial, 2. ${ }^{a}$ ed., Barcelona, 1991.

* Citroni, Gabriella, “Desaparición forzada de personas': desarrollo del fenómeno y respuestas de la Corte Interamericana de Derechos Humanos”, Anuario de Derecho Internacional, 19 (2003).

* Córdoba Roda, Juan / García Arán, Mercedes (dirs.), Comentarios al Código Penal. Parte especial, tomo I, Madrid-Barcelona, 2004.

* Díez Ripollés, José, en ID./Gracia Martín, Luis (coords.), Comentarios al Código Penal. Parte especial, vol. I, Valencia, 1997

* García PÉrez, Octavio, "Delitos de sospecha: principio de culpabilidad y derecho a la presunción de inocencia: los artículos 483 y 485 CP”, Anuario de Derecho Penal y Ciencias Penales, 1993.

* Gimbernat Ordeig, Enrique, "El delito de detención ilegal con desaparición forzada", en AAVV, Estudios Penales en memoria del Profesor Agustín Fernández-Albor, Santiago de Compostela, 1989.

* Hormazábal Malarée, Hernán “Torturas y desaparición forzada de personas”, Revista General de Derecho Penal, 9 (2008), aptdo. 3.1.

* Landrove Díaz, Gerardo, Detenciones ilegales y secuestros, Valencia, 1999

* Martín Pallín, José, "Desaparición forzada de personas: de la sospecha al reproche penal", Actualidad Penal, 1989-1.

* Muñagorri laguía, Ignacio, “La 'construcción’ del delito de detención ilegal con desaparición forzada. La jurisprudencia constitucional y el artículo 483 del Código Penal”, Poder Judicial, 27 (1992).

* Muñoz Conde, Francisco Derecho Penal. Parte especial, 7. a ed., Valencia, 1988

* Queralt y JiméneZ, Joan, Derecho penal español. Parte especial, 5. a ed., 2008.

* Ragués i VALlès, Ramón, "La delimitación entre detenciones ilegales y coacciones. ¿Una tarea condenada al fracaso?", Actualidad Penal, 11 (2003).

* Vives Antón, Tomás, et al., Derecho penal. Parte especial, 2. a ed., Valencia, 1990. 